\title{
A study of triangular membership function and multiple regressions to calculate the MSW compost index
}

\section{DOI : 10.36909/jer.14183}

\author{
Savita Mohurle*, Manoj Devare
}

Department of Computer Science and Engineering, Amity University Mumbai, MumbaiPune Expressway, Bhatan Post- Somathne, Panvel, Mumbai, Maharashtra, India

* Corresponding Author: savitamohurle13@gmail.com

\begin{abstract}
The municipal solid waste compost consists of elements with a varied composition, including light and heavy metal elements. For MSW compost to act as a soil conditioner, and to ensure agricultural stakeholders to believe in its use for crops production, validation of elements is obligatory. The triangular membership function evaluates each element of a fuzzy set for both discrete and continuous values, and regression analysis estimates the relationship between values. In this paper, a triangular membership function $(\mu \mathrm{f})$ is studied and used to characterize the effect of individual elements available in the compost sample. The characterization determines the variation in the composition of elements in the compost

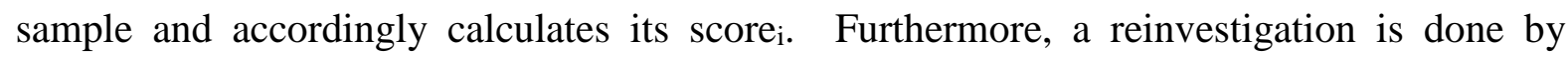
applying multiple regression analysis, especially on heavy metals, to compare their composition with light mineral nutrients and other supplementary elements. A relationship between $\mathrm{R}=4.12$ and $\mathrm{R}^{2}=0.067498635$ is derived to determine the predicted value and defines the composition of heavy metals as attributed to another mineral nutrients. Furthermore, a correlation (Co) is derived to find the performance of the compost sample to decide whether both light and supplementary mineral nutrients are capable of minimizing the
\end{abstract}


effect of heavy metals. A gratuity score $\left(\mathrm{G}_{\mathrm{si}}\right)$ is added to each heavy metal depending on the correlation value to form a compost $\mathrm{i}_{\mathrm{i}}$. The score $_{\mathrm{i}}=88.11$ and compost $\mathrm{i}_{\mathrm{i}}=9.12$ obtained, was summated to derive $C_{i}=97.23$, stating that the increase in score value declares that the compost sample is mature enough to be used for agriculture and enhance crops productivity.

Key words: fuzzy theory; triangular membership; multiple regressions; municipal solid waste; compost index

\section{INTRODUCTION}

The municipal solid waste (MSW) compost consists both of heavy and light metal elements (GOI, 2017), light elements being designated as mineral nutrients and heavy metal elements hazardous for the growth of crops. Moreover, for agricultural stakeholders to believe in the use of compost, its validation and verification are obligatory (Mohurle and Devare, 2020). It is, therefore, required to categorize and predict the composition of compost elements to overcome its adverse effects on crop productivity, mainly heavy metals such as arsenic (As), nickel (Ni), mercury $(\mathrm{Hg})$, chromium $(\mathrm{Cr})$, and cadmium $(\mathrm{Cd})$. The composition of elements in the MSW compost sample is varied and fuzziness prevails (Kumar et al., 2018). Many researcher in their research have studied the effect and cause of individual heavy metal elements and importance of light mineral nutrients on crops growth, like reducing effect of cadmium and arsenic by application of selenium (Zwolak, 2019), role of nitrogen oxide as a positive regulator for plants growth( Santiago et al., 2020), and administration of hydrogen sulfide for germination and plants growth (Francisco and Jose, 2020). Therefore, each element in MSW compost is considered as an element of the fuzzy set that has certain properties and characteristics, represented by a membership function (Babanezhad et al., 2020). Regression analysis, on the other hand, is used to find the uncertain behavior of heavy metal elements to minimize its effect and raise the overall performance of the compost sample to convert waste into wealth (Scnchez et al., 2017). Reinvestigating it through 
regression analysis is significant when compost consists of three categories of data, heavy metal elements, mineral nutrients, and supplementary elements (other mineral nutrients such as selenium, sulfide, $\mathrm{NO}_{2}$, magnesium, iron, vanadium, lime, including vitamins, organic carbon, organic matter (Francisco and Jose, 2020; Chauhan et al., 2019). This paper studies the use of the triangular membership function to segregate the elements in MSW compost. Further, multiple regression is applied to reinvestigate the same sample to minimize the effect of heavy metal elements by deriving $C_{i}$, (Breeze, 2020) as a compost index, to measure its suitability for crops production as shown in Figure 1.

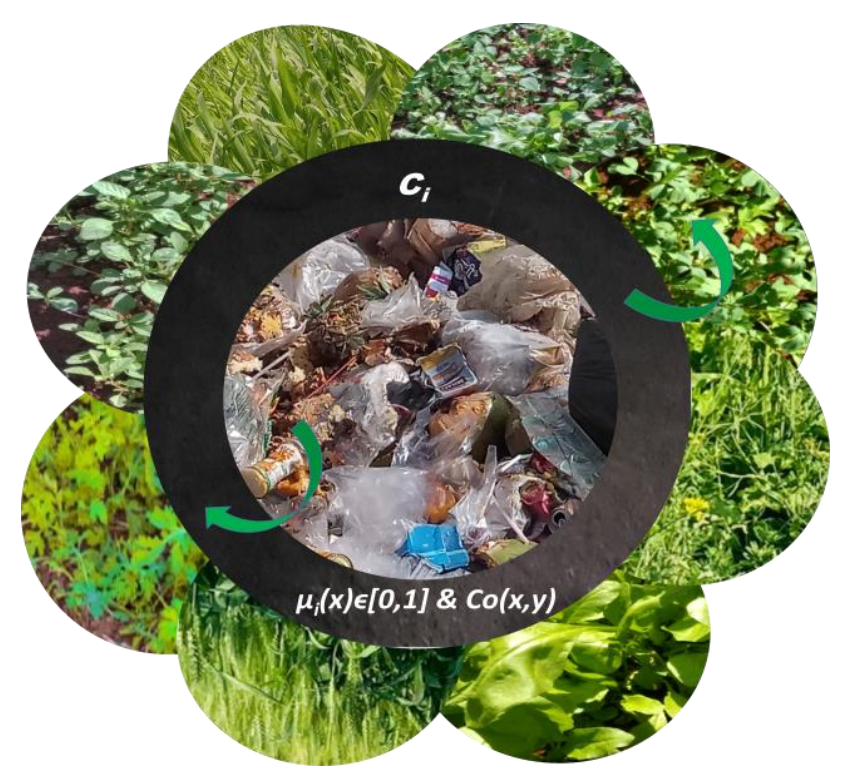

Figure 1 Calculation of $C_{i}$ (Mohurle and Devare, 2020)

\section{MATERIAL AND METHOD}

\section{USE OF TRIANGULAR MEMBERSHIP FUNCTION}

Fuzzy membership represents the degree of truthiness, which covers a range of values between 0 and 1 for every element in the fuzzy set (Abdol and Saeid, 2019). The compost consists of a varied, random, vague, and un-precise composition of elements, which are considered as fuzzy random variables in fuzzy sets (Kumar et al., 2018). A triangular membership function is applied to such elements with composition holding a certain breakpoint to calculate membership value with the following equation 1 : 
$\mathrm{T}=\left(p_{L o}, d_{i}, p_{h i}\right)$

Where, $d_{i}, p_{L o}, p_{h i}$ and $T$, are desirable point, breakpoint that is less than $d_{i}$, breakpoint that is greater than $d_{\mathrm{i}}$, and triangular fuzzy number respectively (Gant, 2020). $p_{L o}$ and $p_{h i}$ breakpoints are tolerance values (composition) for any element to be a part of mature compost. Triangular membership deals with two or more fuzzy numbers in a set by comparing them through the $\max ()$ and the $\min ()$ function (Seresht and Fayek, 2019). The max-min composition is calculated as given in the following equation 2 :

$$
\mu(x)=\max \left(\min \left(\frac{x-p_{L o}}{d_{i}-p_{L o}}, \frac{p_{H i}-x}{p_{H i}-d_{i}}\right), 0\right)
$$

Where $x$ is the element for which membership value is to be computed, $\mu(x)$ is degree of membership for $\mathrm{x}$, while $d_{\mathrm{i}}, p_{L o}$ and $p_{h i}$ are the variable described in equation1. Figure 2 below shows the representation and shape of the triangular membership function trimf() with parameters in vector param, where $d_{i}$ with membership value of 1 that define the peak of the membership function, while $p_{L o}$, and $p_{h i}$ are values that define the feet, $T$ is the triangular fuzzy value $\left(\mu_{\mathrm{A}}(\mathrm{x})\right)$ computed for giving the fuzzy number in the fuzzy set (Dreijer, 2020; Babanezhad et al., 2020). For study, 1000 compost sample consisting of both light (mineral nutrient) and heavy metals is considered. The membership value for the elements in the sample along with density and conductivity is computed. The following python code computes the membership value for each element using fuzzy trimf() for elements composition $x_{1}, x_{2}$, and $x_{3}$ respectively (Dreijer, 2020). The membership value of 1 is identified for a complete membership, 0 with no membership and, $>0$ and $<1$ with non-zero, but not complete membership (Khokhar et al., 2020).

import numpy as $n p$, skfuzzy as fuzz, matplotlib.pyplot as plt
$x=n p$. array $\left(\left[x_{1}, x_{2}, x_{3}\right]\right)$ \# Array of elements in fuzzy set
mfx=fuzz.trimf $\left(x,\left[p_{l o}\right.\right.$, di, $\left.\left.p_{\text {hi }}\right]\right)$ \#Triangular membership function
plt.title('Membership Graph') \# Specify title on X label
plt.plot $(x, m f x, ' r$ ',linewidth=5,label='Linear')\# Plot and print membership
graph


The obtained membership value segregates compost elements into three categories- desirable, permissible, considerable, and forbidden. Hence, a score for a particular sample is calculated with the following equation 3:

$$
\text { score }_{i}=\sum\left(d_{i}, p_{i}, c_{i}\right)
$$

Where $d_{i}, p_{i}, c_{i}$, and $f_{i}$ are desirable, permissible, considerable, and forbidden elements respectively. The $\operatorname{score}_{i}$ is score obtained by summating $d_{i}, p_{i}, c_{i}$, and $f_{i}$.

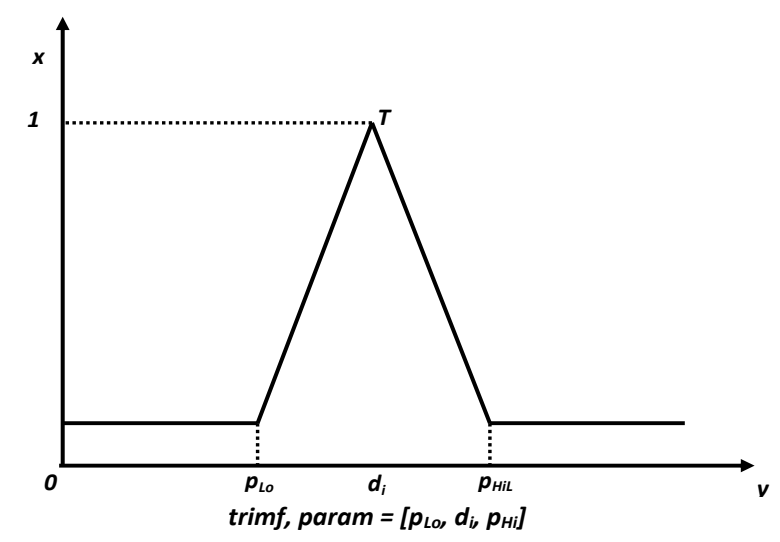

Figure 2. Representation and shape of the Triangular Membership Function (Gant, 2020)

The score $_{i}$ assumes that all light (mineral nutrients) satisfies the requirement specification criteria to be part of healthy and mature compost (GOI, 2017).

\section{USE OF MULTIPLE REGRESSIONS}

Further, to forecast the effect and cause of heavy metal elements available in compost samples, simple multiple regressions are applied (Hao and Hailong, 2020; Yilmazer and Kocaman, 2020). A set $\mathrm{y}=\left\{\mathrm{y}_{0}, \mathrm{y}_{1}, \mathrm{y}_{2}, \mathrm{y}_{3}, \ldots \ldots, \mathrm{y}_{\mathrm{n}}\right\}$ as heavy metal (dependent variable) available in the sample is reinvestigated individually with set $X=\left\{\mathrm{x}_{1}, \mathrm{X}_{2}, \mathrm{X}_{3}, \ldots . . \mathrm{X}_{\mathrm{n}}\right\}$, consisting of all mineral nutrients (independent variables) and other supplementary elements (independent variables). Multiple regression predicts each value of y based on one or more values of $\mathrm{X}$, deriving a correlation between the two (Pun et al., 2019), to determine the strength of heavy metal elements and overcome the weakness of mineral nutrients to acquire a compost index $\left(\mathrm{C}_{\mathrm{i}}\right)$ (Variyath and Brobbey, 2020). In score ${ }_{i}$, as calculated in section 2.1, if any of the heavy elements is forbidden, the sample is reinvestigated. For now, only the heavy 
elements are the input to be measured for calibration by applying multiple regressions with the help of historical inputs (light and supplementary nutrients). The performance of variable $\mathrm{y}$ (heavy element) is forecasted by $\mathrm{X}$ (set of supplementary and other light elements composition) through one - many relationships (GOI, 2017). Figure 3 below shows a schematic of the multiple regression analysis executed on the MSW compost sample.

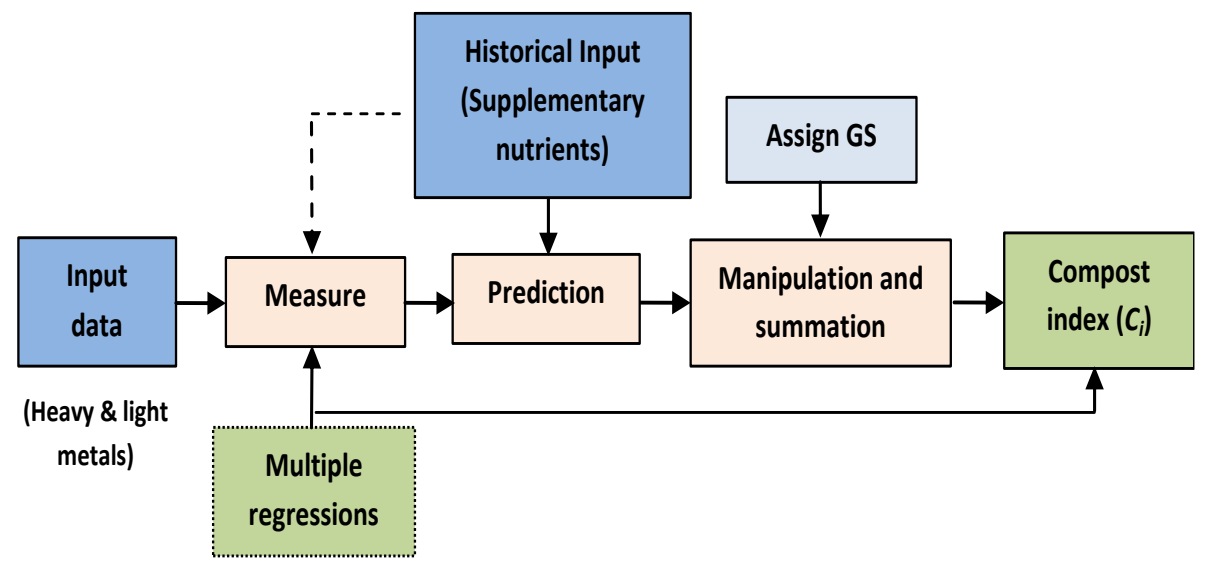

Figure 3 Multiple regressions schematic to forecast heavy metals behavior in compost The value of $\mathrm{pH}$, moisture, and pathogen tests play a vital role in reducing the effect of heavy metals on crop productivity (Chauhan et al., 2019; Scnhez et al., 2017), along with the presence of organic carbon, organic matter, and vitamins that are usually missed out from validation. Multiple regressions perform certain predictions (Kumar et al., 2017) by finding variance and correlation between different data points, verifying fitting lines by estimating the data, and evaluating the validity of data based on which it derives the compost usability index. The covariance states the natural relationship between the data value of $\mathrm{x} \in \mathrm{X}$ and $\mathrm{y}$ (Shams et al., 2020). Here, the covariance between all elements in set $X$ is related to dependent variable $\mathrm{y}$, to estimate the goodness of correlation and also to estimate multiple regressions. Hence, for covariance between heavy metal (y) and mineral nutrients, $\mathrm{x}$ is for all predictor variables in set $\mathrm{X}$ (Tahtali, 2019). The covariance between $\mathrm{x}$ and $\mathrm{y}$ is stated in the following equation 4 :

$$
\operatorname{Cov}(x, y)=\frac{\sum\left(x_{i}-\bar{x}\right)\left(y_{i}-\bar{y}\right)}{n-1}
$$


where $\operatorname{Cov}()$ is the covariance between $x$ and $y, n$ is the number of elements. Multiple regression predicts the overall model parameters $\alpha$ (intercept) and $\beta$ (coefficient) for the joint distribution (Fisher, 2018), of heavy metals, light, and supplementary nutrients. Hence, the response heavy element variable is verified with the presence of predictor variables, which are the supplementary mineral nutrients, organic carbon, and organic matter, to minimize and reduce its effect (Scnchez et al., 2017; Zwolak, 2019; Lu et al., 2019). The following python code is executed to predict heavy metal value (Mohurle and Devare, 2020):

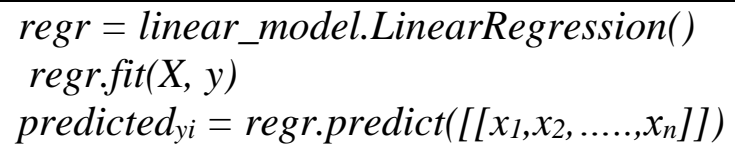

Depending on the correlation and predicted response variable value of heavy metal, a gratuity score $\left(\mathrm{G}_{\mathrm{y}}\right)$ in terms of the composition of each supplementary element in the sample is assigned as $G_{y 0}, G_{y 1}, G_{y 2}, G_{y 3}, \ldots . ., G_{y n}$, respectively, to add up to the final index. The heavy element value predicted $d_{y i} \approx y_{i}$, predicted by providing predictors, either follows the condition of nearness, farness, or exactness to the requirement specification as given in table below:

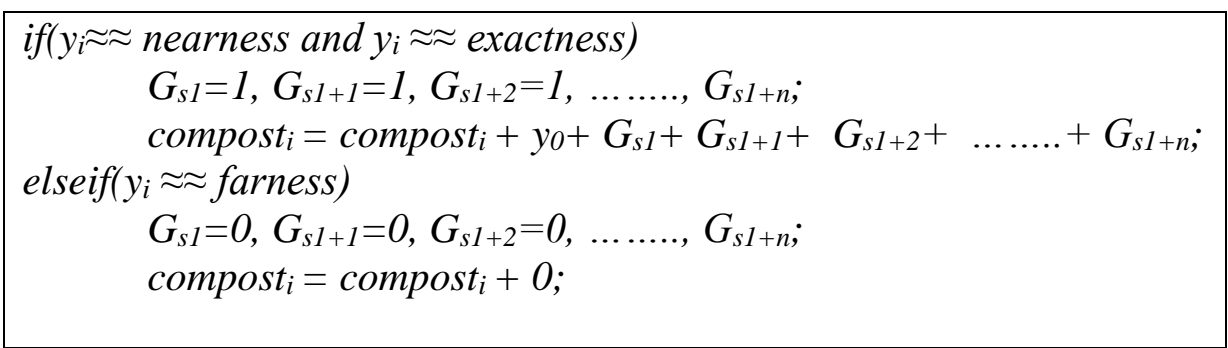

Where, compost $_{i}=$ compost $_{i}+y($ predicted heavy elements value $)+G_{y}$ (corresponding Gratuity scores for respective heavy elements))/(Total number of elements in the sample). Hence, a final compost sample usability index is calculated by using the following equation 5: $C_{i}=$ score $_{i}+$ compost $_{i}$

The $C_{i}$ is the summation of score $_{i}$ calculated in section 1 and compost $t_{i}$, for a sample where heavy metal reduces the compost sample maturity. 


\section{RESULTS}

A MSW compost sample with elements carbon $(\mathrm{C}=20)$, nitrogen $(\mathrm{N}=1.8)$, phosphorus $(\mathrm{ph}=0.5)$, phosphorus pentoxide $\left(\mathrm{P}_{2} \mathrm{O}_{5}=1.9\right)$, potassium oxide $\left(\mathrm{K}_{2} \mathrm{O}=1.9\right)$, $\operatorname{arsenic}(\mathrm{As}=7)$, $\operatorname{admium}(\mathrm{Cd}=8)$, $\operatorname{chromium}(\mathrm{Cr}=45), \quad \operatorname{copper}(\mathrm{Cu}=299), \quad$ lead$(\mathrm{Pb}=98.67), \quad \operatorname{nickel}(\mathrm{Ni}=45), \quad \operatorname{zinc}(\mathrm{Zn}=999), \quad$ and mercury $(\mathrm{Hg}=0.15)$ in composition $\mathrm{mg} / \mathrm{kg}$ respectively, including moisture level =22.8, $\mathrm{C}: \mathrm{N}=22$, density $=1.9$, conductivity $=4.6$ and $\mathrm{pH}=6.8$ is considered for study. Table 1(a) and 1(b) below (as discussed in section 1) shows computed membership values mAs, mNi, mHg, $\mathrm{mCr}$ and $\mathrm{mCd}$ for Arsenic (As), Nickel (Ni) and Mercury (Hg),Chromium (Cr), and Cadmium (Cd) respectively for 30 compost samples using trimf(). Table 2 shows (as discussed in section 1) the output of the triangular membership function, classifying elements of a compost sample into desirable $\left(d_{i}\right)$, permissible $\left(p_{i}\right)$, considerable $\left(c_{i}\right)$ and forbidden $\left(f_{i}\right)$, where $d_{i}, p_{i}$ and $c_{\mathrm{i}}$ are the elements that meet the requirement specification (GOI, 2017), while $f_{i}$ is elements whose composition is higher than expected. The score comes out to be 88.11 , which is fairly acceptable and can be applied to specific types of crops

Table 1. The membership value computed for heavy metals $\mathrm{Cd}, \mathrm{Cr}, \mathrm{As}, \mathrm{Ni}$ and $\mathrm{Hg}$ respectively is considerable (Babanezhad et al., 2020; Kohkhar et al., 2020)

\begin{tabular}{|c|c|c|c|c|c|c|c|c|c|}
\hline $\mathbf{C d}$ & $\boldsymbol{\mu}(\mathbf{C d})$ & $\mathbf{C r}$ & $\boldsymbol{\mu}(\mathbf{C r})$ & $\mathbf{A s}$ & $\boldsymbol{\mu}(\mathbf{A s})$ & $\mathbf{N i}$ & $\boldsymbol{\mu}(\mathbf{N i})$ & $\mathbf{H g}$ & $\boldsymbol{\mu}(\mathbf{H g})$ \\
\hline 15.89 & 0.0 & 15.89 & 0.636 & 8.45 & 0.425 & 54.8 & 0.0 & 0.01 & 0.0 \\
\hline 32.89 & 0.0 & 32.89 & 0.708 & 9.67 & 0.222 & 16.56 & 0.648 & 0.15 & 0.4 \\
\hline 11.08 & 0.0 & 11.08 & 0.443 & 12.55 & 0.0 & 50.28 & 0.028 & 0.06 & 0.769 \\
\hline 6.5 & 0.0 & 6.5 & 0.26 & 7.46 & 0.59 & 52.3 & 0.0 & 0.015 & 0.077 \\
\hline 4.5 & 0.0 & 4.5 & 0.18 & 5.67 & 0.888 & 9.34 & 0.347 & 0.02 & 0.154 \\
\hline 19.88 & 0.0 & 19.88 & 0.795 & 5.44 & 0.927 & 9.28 & 0.345 & 0.01 & 0.0 \\
\hline 8.0 & 0.0 & 45.0 & 0.259 & 4.5 & 0.875 & 45.0 & 0.231 & 0.15 & 0.4 \\
\hline 7.9 & 0.0 & 7.9 & 0.316 & 6.92 & 0.68 & 14.56 & 0.565 & 0.104 & 0.768 \\
\hline 16.57 & 0.0 & 16.57 & 0.663 & 7.89 & 0.518 & 17.78 & 0.699 & 0.21 & 0.0 \\
\hline 12.8 & 0.0 & 12.8 & 0.512 & 5.66 & 0.89 & 21.68 & 0.862 & 0.03 & 0.308 \\
\hline 14.8 & 0.0 & 14.8 & 0.592 & 9.18 & 0.303 & 45.2 & 0.223 & 0.015 & 0.077 \\
\hline 19.6 & 0.0 & 19.6 & 0.784 & 5.99 & 0.835 & 18.39 & 0.725 & 0.013 & 0.046 \\
\hline 31.9 & 0.0 & 31.9 & 0.744 & 6.94 & 0.677 & 19.49 & 0.77 & 0.012 & 0.031 \\
\hline 40.0 & 0.0 & 40.0 & 0.444 & 8.33 & 0.445 & 23.95 & 0.956 & 0.4 & 0.0 \\
\hline 45.9 & 0.0 & 45.9 & 0.226 & 7.67 & 0.555 & 21.69 & 0.862 & 0.011 & 0.015 \\
\hline
\end{tabular}




\begin{tabular}{|c|c|c|c|c|c|c|c|c|c|}
48.0 & 0.0 & 48.0 & 0.148 & 8.4 & 0.433 & 45.2 & 0.223 & 0.0123 & 0.035 \\
\hline 49.99 & 0.0 & 49.99 & 0.074 & 6.89 & 0.685 & 56.34 & 0.0 & 0.01 & 0.0 \\
\hline 51.02 & 0.0 & 51.02 & 0.036 & 9.0 & 0.333 & 21.69 & 0.862 & 0.44 & 0.0 \\
\hline 6.89 & 0.0 & 6.89 & 0.276 & 7.32 & 0.613 & 32.56 & 0.709 & 0.13 & 0.56 \\
\hline 5.99 & 0.003 & 5.99 & 0.24 & 6.5 & 0.75 & 6.059 & 0.211 & 0.21 & 0.0 \\
\hline 2.4 & 0.7 & 2.4 & 0.096 & 7.8 & 0.533 & 7.996 & 0.292 & 0.16 & 0.32 \\
\hline 4.883 & 0.372 & 4.883 & 0.195 & 8.5 & 0.417 & 5.34 & 0.181 & 0.18 & 0.16 \\
\hline 14.3 & 0.0 & 14.3 & 0.572 & 7.56 & 0.573 & 4.67 & 0.153 & 0.1342 & 0.526 \\
\hline 56.8 & 0.0 & 56.8 & 0.0 & 9.2 & 0.3 & 13.78 & 0.532 & 0.21 & 0.0 \\
\hline 3.4 & 0.867 & 3.4 & 0.136 & 5.66 & 0.89 & 45.8 & 0.2 & 1.02 & 0.0 \\
\hline 6.99 & 0.0 & 6.99 & 0.28 & 7.32 & 0.613 & 51.23 & 0.0 & 0.01 & 0.0 \\
\hline 13.92 & 0.0 & 13.92 & 0.557 & 6.5 & 0.75 & 50.78 & 0.008 & 0.19 & 0.08 \\
\hline 18.35 & 0.0 & 18.35 & 0.734 & 7.8 & 0.533 & 53.2 & 0.0 & 1.02 & 0.0 \\
\hline 16.92 & 0.0 & 16.92 & 0.677 & 8.5 & 0.417 & 12.68 & 0.487 & 0.14 & 0.48 \\
\hline 23.89 & 0.0 & 23.89 & 0.956 & 7.56 & 0.573 & 6.57 & 0.232 & 0.176 & 0.192 \\
\hline
\end{tabular}

But in the same sample, the composition of $\mathrm{Cd}$ and $\mathrm{C}$ is forbidden, as shown in table 2 above.

The element Cd is a heavy metal ( Lu et al., 2019). Reinvestigation is needed to increase

sample usability and additional nutrients needs to be added to reduce its effect (Chetan et al., 2019). After applying multiple regression, the analysis values (R) for Cd appeared to be 4.12

Table 2. Segregation of elements into three categories- desirable, permissible, and considerable (Babanezhad et al., 2020; Kohkhar et al., 2020)

\begin{tabular}{|c|c|c|c|c|c|c|}
\hline $\begin{array}{c}\text { Mineral } \\
\text { Nutrients } \\
\end{array}$ & Composition & Membership & Desirable & Permissible & Considerable & Forbidden \\
\hline Moisture & 22.800 & 0.440 & 22.800 & nil & Nil & Nil \\
\hline Nitrogen & 1.800 & 0.400 & Nil & 1.800 & Nil & Nil \\
\hline P2O5 & 1.900 & 0.200 & Nil & 1.900 & Nil & Nil \\
\hline $\mathrm{K} 2 \mathrm{O}$ & 1.900 & 0.200 & Nil & 1.900 & Nil & Nil \\
\hline Cd & 8 & 0 & Nil & nil & Nil & 8 \\
\hline Carbon & 20 & 0 & Nil & nil & Nil & 20 \\
\hline $\mathrm{C}: \mathrm{N}$ & 22 & 0.620 & Nil & 22 & Nil & Nil \\
\hline Zinc & 999 & 0.500 & Nil & 999 & Nil & Nil \\
\hline Lead & 98.670 & 0.557 & Nil & nil & 98.670 & Nil \\
\hline Copper & 299 & 0.750 & Nil & 299 & Nil & nil \\
\hline pH & 6.800 & 0.667 & Nil & 6.800 & Nil & nil \\
\hline As & 4.500 & 0.000 & Nil & nil & Nil & nil \\
\hline $\mathbf{N i}$ & 45 & 0.000 & Nil & nil & Nil & nil \\
\hline $\mathrm{Cr}$ & 45 & 0.900 & 45 & nil & Nil & nil \\
\hline Hg & 0.150 & 1 & 0.150 & nil & Nil & nil \\
\hline Phosphorus & 0.500 & 1 & 0.500 & nil & Nil & nil \\
\hline Density & 1.900 & 0.400 & 1.900 & nil & Nil & nil \\
\hline Conductivity & 4.600 & 0.800 & 4.600 & nil & Nil & nil \\
\hline
\end{tabular}


for a particular composition of $\operatorname{zinc}(\mathrm{Zn}=1000)$, selenium $(\mathrm{Se}=0.5)$, magnesium $(\mathrm{Mg}=1)$, $\operatorname{iron}(\mathrm{Fe}=67)$, sulfide $=8.3$ respectively, as supplementary nutrients, in the presence of lime, organic matter, and organic carbon, which is near to the acceptable value of Cd (GOI, 2017). Figure 4(a) and 4(b) show the correlation graph and, the variance between the composition of $\mathrm{Cd}$ (heavy element) and supplementary nutrients ( $\mathrm{Se}, \mathrm{Zn}, \mathrm{Mg}, \mathrm{Fe}$, and sulfide) signifying that if the composition of supplementary nutrients increases, the effect of heavy metal elements decreases as discussed in section 2. The $\mathrm{R}^{2}=0.067498635$ (approximately) represents the composition of $\mathrm{Cd}$ varies with other supplementary elements. The standard error comes out to be 2.071084097 for 1000 observations. The coefficients for $\mathrm{Zn}, \mathrm{Se}, \mathrm{Mg}, \mathrm{Fe}$, and sulfide are $0.000921397,0.957793034,0.310604822,0.02908208$, and 0.2376881 respectively.

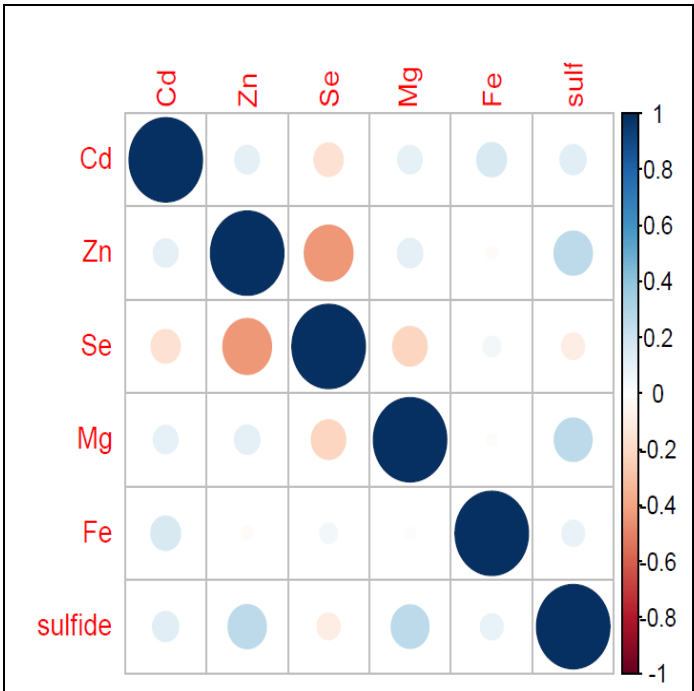

Figure 4(a). The variance and correlation between the composition of $\mathrm{Cd}$ (heavy element) and supplementary nutrients ( $\mathrm{Se}, \mathrm{Zn}, \mathrm{Mg}$, $\mathrm{Fe}$, and sulfide)

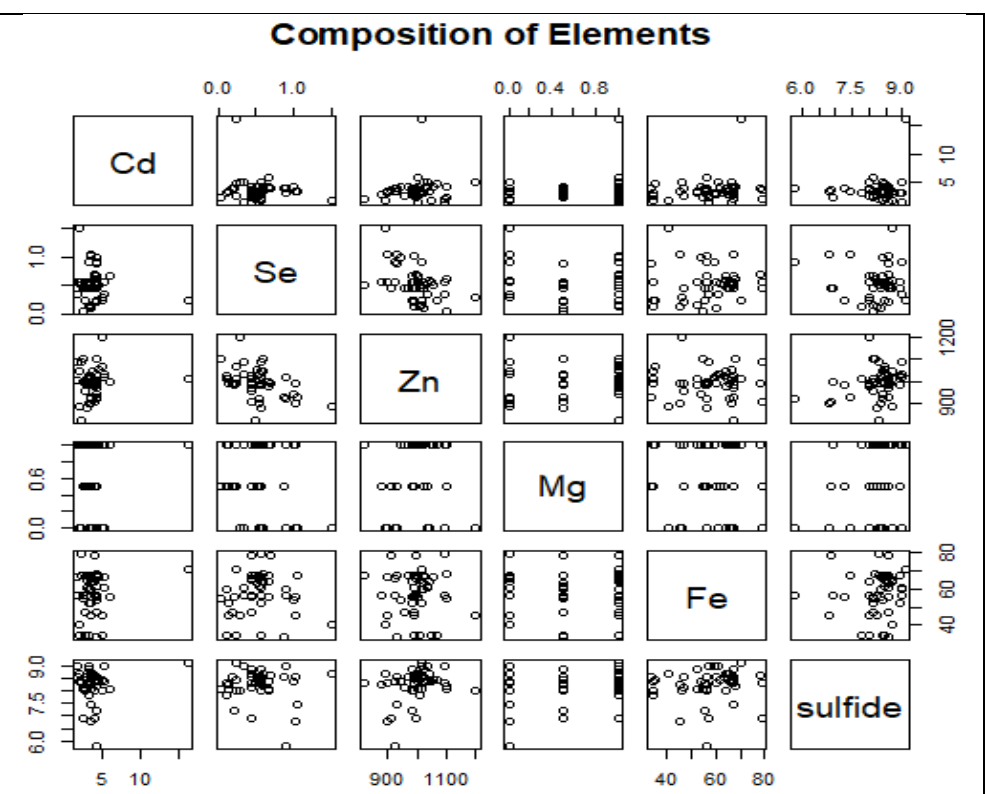

Figure 4(b). The correlation graph between Cd (heavy element) and supplementary nutrients ( $\mathrm{Se}, \mathrm{Zn}, \mathrm{Mg}, \mathrm{Fe}$, and sulfide)

For manipulation, a gratuity score $\left(G_{s}\right)$ is set for each supplementary mineral nutrient as per its availability in a particular sample, to minimize the effect of $\mathrm{Cd}$, and the compost value is 9.12. Further, the compost value is summated with the score to improve its performance and 
the compost usability index $\left(C_{i}\right)$ is calculated for such a sample that failed to qualify for its usability for crops (Breeze, 2020). After reinvestigating Cd, the compost usability index came out to be $C_{i}=97.23$ as shown in figure 5 . The score calculated using the triangular membership function is 88.11 , where the composition of heavy metal $\mathrm{Cd}$ and the composition of carbon is more than the requirement. Hence, to increase the usability of the sample, a multiple regression is applied and $C_{i}$ gradually increases to be 97.23 which is acceptable, signifying that extra mineral nutrients in compost improve crop productivity. Likewise, covariance, correlation, and multiple regressions of all the remaining four heavy metal elements $\left(\mathrm{y}_{1}=\mathrm{Ni}\right.$, $\mathrm{y}_{2}=\mathrm{Ch}, \mathrm{y}_{3}=\mathrm{As}$, and $\mathrm{y}_{4}=\mathrm{Hg}$ in set $\mathrm{y}$ ) if any forbidden, can be calculated

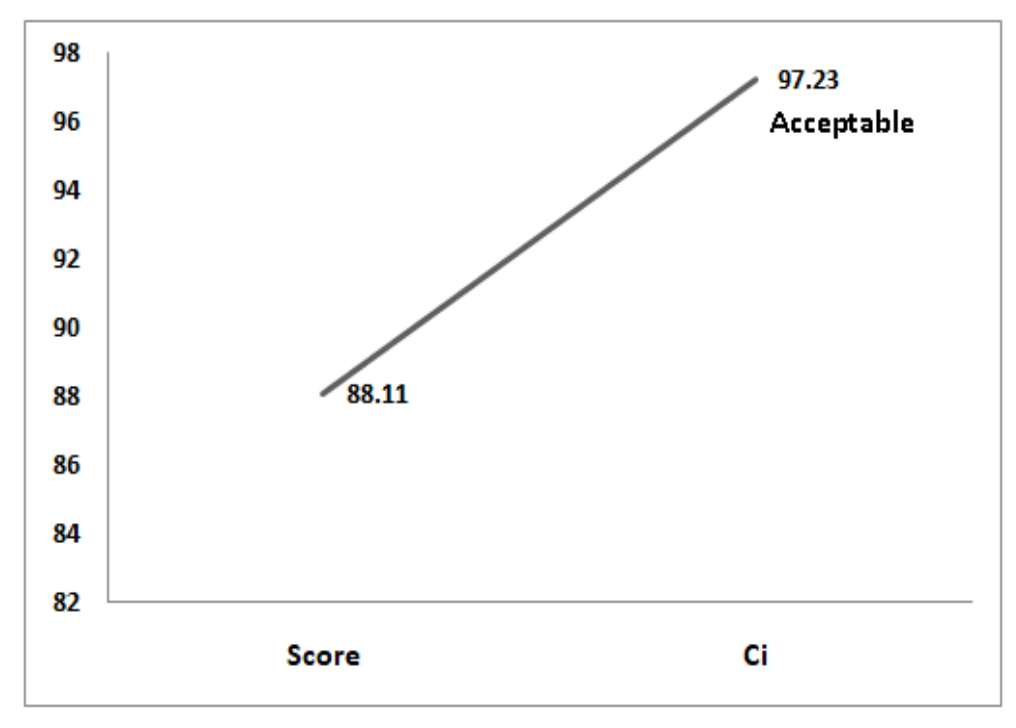

Figure 5 Increase in score $_{i}$ by adding compost $t_{i}$ to derive $C i$

to find predictions by providing both light elements (mineral nutrients) and supplementary elements for a particular sample

\section{CONCLUSION}

- The triangular membership function analyzed the compost sample and multiple regressions indicated the strength and weakness of elements in the compost.

- Use of trimf() and multiple regressions $\operatorname{Cov}()$, derived a discrete value $C_{i}$ for MSW compost sample. 
- The compost index findings signify the quality of compost hence, states its effectiveness and acceptance level.

- Further, a compost quality (CQ) can be calculated by classifying the index in some specific range, detailing it with certain characteristics and symbols or tags.

\section{REFERENCES}

Abdol, Z., \& Saeid, E. 2019. The performance of fuzzy regression for estimating of reference evapotranspiration under controlled environment. International Journal of Hydrology Science and Technology 9(1):28-37. https:// doi: 10.1504/IJHST.2019.096791

Babanezhad, M., Masoumian, A., Nakhjiri, A., Marjani, A., \& Shirazian, S. 2020. Influence of number of membership functions on prediction of membrane systems using adaptive network based fuzzy inference system (ANFIS). Scientific Research Nature search 10, 16110. https://doi.org/10.1038/s41598-020-73175-0.

Breeze Technologies. 2020. How to calculate our Air quality Index and Why we need it?. https://www.breeze-technologies.de/blog/what-is-an-air-quality-index-how-is-itcalculated/.

Chauhan, R., Awasthi, S., Srivastava, S., Dwivedi, S., Pilon-Smita, E., Dhankher, O., \& Tripathi, R. 2019. Understanding selenium metabolism in plants and its role as beneficial elements. Critical Reviews in Environmental Science and Technology 49(21): 1937-1958. https://doi.org/10.1080/10643389.2019.1598240.

Chetan, J., Sandeep, K., \& Ram, M. 2019. Significance of Soil Organic Matter to Soil Quality and Evaluation of Sustainability. Sustainable Agriculture 357-381.

Dreijer, J., 2020. skfuzzy 0.3 doc, https://scikit-fuzzy.readthedocs.io/ en/latest/userguide/getting started.html.

Fisher, R., Wilson, S., Sin, T., Lee, A., \& Langlois, T. 2018. A simple function for fullsubsets multiple regression in ecology with R. Ecology and Evolution 8(12): 1-10. https://doi.org/10.1002/ece3.4134. 
Francisco, C., \& Jose, P. 2020. $\mathrm{H}_{2} \mathrm{~S}$ signaling in plants and application in agricultural, Journal of Advanced Research 24:131-137. https://doi:10.1016/j.jare.2020.03.011

Gant, P. 2020. Understanding Multiple Regression. $\underline{\text { https:// }}$ owardsdatascience.com/understanding-multiple-regression-249b16bde83e.

GOI-Government of India. 2017. The Fertilizers (Control) Order 1985. https:// krishi.maharashtra.gov.in/1062/Fertilizer-Control-Order-1985.

Hao, H., and Hailong, Z. 2020. Description and Application Research of Multiple Regression Model Optimization Algorithm Based on Data Set Denoising. Journal of Physics: Conference Series 1631(2020) 012063:1-7. https:// doi:10.1088/1742$6596 / 1631 / 1 / 012063$.

Kumar, P., Parimi, A., and Rao, U. 2017. Solar Illumination And Wind Speed Prediction: The Relative Prospects and Potential outcomes. Journal of Electrical Engineering. 17(1.35):28:1-8. EID:2s-2.0-85019057011.

Kumar, S., Negi, S., Mandpe, A., Singh, R., \& Hussian, A. 2018. Rapid Composting techniques in Indian context and utilization of black solider fly for enhanced decomposition of biodegradable wastes- A comprehensive review. Journal of Environmental Management 227: 189-199. https://10.1016/j.jenvman.2018.08.096.

Khokhar, S., Peng, Q., Asif, A., Noor, M., \& Inam, A., 2020. A Simple Tuning Algorithm of Augmented Fuzzy Rapid Composting techniques Membership Functions. IEEE Access 8, 35805-35814. https://doi.org/10.1109/ACCESS.2020.2974533.

Lu, Y., Wang, Q., Li., J., Xiong, J., Zhou, L., He, S., Zhang, J., Chen, Z. , He, S., \& Lui, H. 2019. Effects of exogenous sulfur on alleviating cadmium stress in tartary buckwheat Applications in R and SPSS. Sci. Rep. 9, 7397. https://doi.org/10.1038/s41598-01943901-4.

Mohurle, S., \& Devare, M. 2020. Fuzzy Probability Model for quantifying effectiveness of MSW Compost. 2019 International Conference on Nascent Technologies in Engineering (ICNTE), IEEE Digital Xplore. https://doi:10.1109/ICNTE44896.2019.8945830. 
Pun, L., Zhao, P., \& Liu, X. 2019. A Multiple Regression Approach for Traffic Flow $\begin{array}{llll}\text { Estimation. } & \text { IEEE } & \text { Access } & \text { 7(1-1):35998-36009. }\end{array}$ https://doi.org/10.1109/ACCESS.2019.2904645.

Santiago, S., Martha, S., Sofia, T., R., \& Jorge, M. 2020. The Role of Nitric Oxide in Nitrogen Fixation by Legumes. Frontiers in Plant Science 11:521. https://doi.org/ $\underline{10.3389 / \text { fpls.2020.00521 }}$

Scnchez, O., Ospina, D. \& Montoya, S. 2017. Compost supplementation with nutrients and $\begin{array}{llll}\text { microorganism } & \text { process. } & \text { Waste } & \text { Management }\end{array}$ https://doi.org/10.1016/j.wasman.2017.08.012.

Seresht, N., \& Fayek, A. 2019. Computational method for fuzzy arithmetic operations on triangular fuzzy numbers by extension principles. International Journal of Approximation Reasoning 106:172-193. https://doi.org/10.1016/j.ijar.2019.01.005.

Shams, R., Jahani, A., Moeinaddini, M., \& Khorasani, N. 2020. Air carbon monoxide forecasting using an artificial neural network in comparison with multiple regressions. Modeling Earth Systems and Environment 6(4). https://doi.org/10.1007/s40808-02000762-5

Tahtali, Y. 2019. Use of factor scores in multiple regression analysis for estimation of body weight by certain body measurements in Romanov Lambs. PeerJ 1-11. https://doi.org/10.7717/peerj.7434.

Variyath, AM., \& Brobbey, A. 2020. Variable selection in multivariate multiple regression. PLoS ONE 15(7): e0236067. https://doi.org/10.1371/journal.pone.0236067.

Yilmazer, S., \& Kocaman, S. 2020. A mass appraisal assessment study using machine learning based on multiple regression and random forest. Land Use Policy 99:104889. https://doi.org/:10.1007/s12011-019-01691-w.

Zwolak, I. 2019. The Role of Selenium in Arsenic and Cadmium Toxicity: an Updated Review of Scientific Literature, Biol. Trac. Elem. Res. 193: 44-63, https://doi.org/10.1007/s12011-019-01691-w. 